RESEI1/GQA-A22874
AUG $20{ }_{1998}$ GA-A
OS, CONF-980560-.

\title{
IMPURITY ENRICHMENT AND RADIATIVE ENHANCEMENT USING INDUCED SOL FLOW IN DIII-D
}

by

M.R. WADE, W.P. WEST, R.D. WOOD, S.L. ALLEN, J.A. BOEDO, N.H. BROOKS, M.E. FENSTERMACHER, D.N. HILL, J.T. HOGAN, R.C. ISLER, G.L. JACKSON, C.J. LASNIER, R. LEHMER, A.W. LEONARD, M.A. MAHDAVI, R. MAINGI, R.A. MOYER, T.H. OSBORNE, T.W. PETRIE, M.J. SCHAFFER, R.D. STAMBAUGH, J.G. WATKINS, and D.G. WHYTE

DISTRIBUTION OF THIS DOCUNENT IS URLMTRED

JULY 1998 


\section{DISCLAIMER}

This report was prepared as an account of work sponsored by an agency of the United States Government. Neither the United States Government nor any agency thereof, nor any of their employees, makes any warranty, express or implied, or assumes any legal liability or responsibility for the accuracy, completeness, or usefulness of any information, apparatus, product, or process disclosed, or represents that its use would not infringe privately owned rights. Reference herein to any specific commercial product, process, or service by trade name, trademark, manufacturet, or otherwise does not necessarily constitute or imply its endorsement, recommendation, or favoring by the United States Government or any agency thereof. The views and opinions of authors expressed herein do not necessarily state or reflect those of the United States Government or any agency thereof. 


\section{DISCLAIMER}

Portions of this document may be illegible electronic image products. Images are produced from the best available original document. 


\title{
IMPURITY ENRICHMENT AND RADIATIVE ENHANCEMENT USING INDUCED SOL FLOW IN DIII-D
}

\author{
by
}

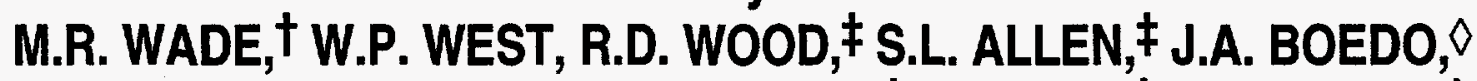
N.H. BROOKS, M.E. FENSTERMACHER, $¥$ D.N. HILL,, J.T. HOGAN, ${ }^{\dagger}$ R.C. ISLER, † G.L. JACKSON, C.J. LASNIER,, R. LEHMER, $\diamond$ A.W. LEONARD, M.A. MAHDAVI, R. MAINGI, † R.A. MOYER, $\diamond$ T.H. OSBORNE, T.W. PETRIE, M.J. SCHAFFER, R.D. STAMBAUGH, J.G. WATKINS, $\Delta$ and D.G. WHYTE $\diamond$

This is a preprint of a paper to be presented at the 13th International Conference on Plasma Surface Interactions in Controlled Fusion Devices, May 18-23, 1998, San Diego, California and to be published in Journal of Nuclear Materials.

†Lawrence Livermore National Laboratory

¥0ak Ridge National Laboratory

$\vartheta$ Princeton Plasma Physics Laboratory

$\Delta$ University of California, San Diego

\author{
Work supported by \\ the U.S. Department of Energy \\ under Contracts DE-AC03-89ER51114, DE-AC05-960R22464, \\ W-7405-ENG-48, DE-AC02-76CH03073, and Grant DE-FG03-95ER54294
}

\section{GA PROJECT 3466}

JULY 1998 


\section{ABSTRACT}

Experiments on DIII-D have demonstrated the efficacy of using induced scrape-off-layer (SOL) flow to preferentially enrich impurities in the divertor plasma. This SOL flow is produced through simultaneous deuterium gas injection at the midplane and divertor exhaust. Using this SOL flow, an improvement in enrichment (defined as the ratio of impurity fraction in the divertor to that in the plasma core) has been observed for all impurities in trace-level experiments (i.e., impurity level is non-perturbative), with the degree of improvement increasing with impurity atomic number. In the case of argon, exhaust gas enrichment using modest SOL flow is as high as 17. Using this induced SOL flow technique and argon injection, radiative plasmas have been produced that combine high radiation losses $\left(\mathrm{P}_{\mathrm{rad}} / \mathrm{P}_{\text {input }}>70 \%\right)$, low core fuel dilution $\left(\mathrm{Z}_{\text {eff }}\right.$ $<1.9)$, and good core confinement $\left(\tau_{\mathrm{E}}>1.0 \tau_{\mathrm{E}, \mathrm{ITER} 93 \mathrm{H}}\right)$. 
$\gamma$ 


\section{INTRODUCTION}

In future, high power density fusion devices, protecting the integrity of the divertor target plates through the maintenance of acceptable erosion rates and thermal heat load is a key constraint on the design of a reactor-grade tokamak. Maintaining acceptable power load on these target plates will require the dispersal of a large fraction of the plasma heat efflux either through radiative or collisional processes in the core and divertor plasma. Computational studies for future devices have shown that hydrogenic radiation alone will not be sufficient to provide the necessary radiative losses; thus, additional radiation via impurities (either intrinsic or seeded) will be required for high power density designs [1]. The amount of impurities that can be tolerated is generally limited as the above constraint must be weighed equally with the requirement to maintain good core energy confinement and acceptable fuel dilution. One method for achieving these goals simultaneously is preferential enrichment (i.e., higher concentration) of impurities in the divertor region. One such approach developed on DIII-D is the "puff and pump" technique in which a strong main ion flow is induced in the scrape-off-layer (SOL) via strong deuterium gas injection near the stagnation point combined with divertor exhaust to produce a strong frictional drag force on the impurities in the SOL [2-4]. The efficacy of this technique has been demonstrated not only in trace level experiments where impurity enrichment is observed to increase with the applied SOL flow but also in radiative level experiments using argon. Plasma conditions have been produced with $\mathrm{P}_{\text {rad }} / \mathrm{P}_{\text {input }}>70 \%$, $\left(\mathrm{P}_{\text {rad,div }}+\mathrm{P}_{\text {rad,SOL }}\right) / \mathrm{P}_{\text {input }}>50 \%, \mathrm{Z}_{\text {eff }}<$ 1.9 and $\tau_{\mathrm{E} / \mathrm{E}, \mathrm{ITER} 93 \mathrm{H}}>1.0$. Here, $\mathrm{P}_{\text {rad }}$ is the total radiated power, $\mathrm{P}_{\text {input }}$ is the total input power, $\mathrm{P}_{\text {rad,div }}$ and $\mathrm{P}_{\text {rad,SOL }}$ is the radiated power in the divertor and SOL region, respectively, $\tau_{\mathrm{E}}$ is the energy confinement time, and $\tau_{E, I T E R} 93 \mathrm{H}$ is the energy confinement time predicted by the ITER $\mathrm{H}$-mode confinement scaling database [5]. Details of these experiments are presented here.

In developing quantitative criteria for present-day experiments, a reasonable starting point is the design of the International Thermonuclear Experimental Reactor (ITER). The constraints listed above have led to the following ITER design criteria [6]: $\mathrm{P}_{\text {target }} /\left(\mathrm{P}_{\text {input }}+\mathrm{P}_{\alpha}\right)<16 \%$,

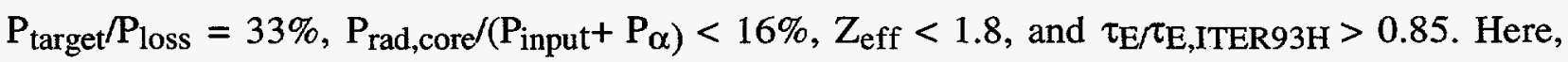
$\mathrm{P}_{\text {target }}$ is the power conducted to the target plate, $\mathrm{P}_{\text {loss }}$ is the power flowing out of the core (i.e., $\left.P_{\text {input }}+P_{\alpha}-P_{\text {rad,core }}\right), P_{\text {input }}$ is the input power, $P_{\alpha}$ is the fusion power, and $P_{\text {rad,core }}$ is the power from line radiation in the core plasma. Extensive campaigns have been carried out on a variety of machines in hopes of obtaining a solution that meets all of these criteria. To date, the best results have been obtained by using strong deuterium gas injection $[7,8]$. In this case, the divertor plasma is detached (i.e., plasma flow to the divertor plate is negligible) from the divertor 
target at the separatrix but remains attached further out in the SOL. Using this method, plasmas

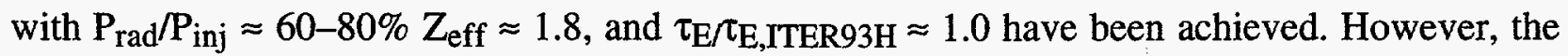
majority of the radiated power in these cases results from intrinsic impurities that are evolved from the material surfaces during a discharge, which in a reactor are the same surfaces that one is trying to protect. Hence, one would like to find a solution which uses seeded impurities, preferably recycling impurities such as neon, argon, etc. To date, the introduction of impurities into $\mathrm{H}$-mode plasmas to enhance radiation has generally resulted in unacceptable impurity levels in the core plasma, producing high levels of fuel dilution $\left(Z_{\text {eff }}>2.5\right)$ and in the worst cases, a return to L-mode as the power flow through the edge is reduced below the level required to maintain $\mathrm{H}$-mode confinement [9].

Inducing a strong, target-directed flow in the edge region is one means of combating this unacceptably high impurity accumulation in the core plasma. In DIII-D, this is accomplished through the use of strong $\mathrm{D}_{2}$ injection at the midplane coupled with divertor exhaust. This "puff and pump" technique is predicated upon the assumption that collisional transport dominates the transport of impurity ions in the SOL and divertor. Neglecting electric field effects and crossfield transport, the two main forces acting on impurity ions in the SOL are the frictional drag imposed on the impurities by the background plasma and the collisional thermal force $[10,11]$. The thermal force is generally present throughout the SOL and acts to drive impurities up the thermal gradient towards the core plasma. Therefore, the frictional drag associated with the flow of the background plasma towards the divertor target must be of sufficient strength to overcome this tendency for impurities to drift towards the core plasma. Under what we will term "natural" flow conditions (i.e., without external augmentation of the flow in the SOL) the parallel flow of the bulk plasma ions in the SOL is small and is directed from the core plasma toward the divertor target. It becomes large only near the ionization region in the divertor, where there is local flow (or flux) amplification due to recycled neutral ions [12]. The premise of the "puff and pump" technique is to augment the bulk plasma ion flow in the SOL sufficiently so that a strong, targetdirected primary ion flow exists throughout the entire radial width of the SOL. Additional benefit is gained through lowering of the SOL and divertor ion temperature, which also increases the frictional force and reduces the thermal gradient force.

Experiments have demonstrated that this technique is effective in increasing the enrichment of impurities in the DIII-D divertor [2,3], with the improvement being substantial for higher $\mathrm{Z}$ impurities [4]. Details of these measurements as well as other observed virtues of using the "puff and pump" technique, namely an extremely thick SOL and reduced amplitude ELMs, will be discussed in Section 2. On the basis of these results, an extensive campaign has recently been carried out in which argon injection in concert with the strong, induced SOL flow has been used 
to produce radiative edge and divertor conditions. Using the method, conditions that are commensurate with the ITER requirements outlined above have been obtained. The details of these experiments are presented in Section 3. 
6 


\section{VIRTUES OF THE TECHNIQUE}

The ability to induce a strong main ion flow in the SOL without causing a concomitant increase in plasma density is predicated upon obtaining a balance between the deuterium injection rate and the divertor cryopump exhaust rate. In DIII-D, deuterium throughput rates up to $2.5 \times 10^{22} \mathrm{D} \%$ s have been maintained without substantive increases in plasma density or degradation in $\mathrm{H}$-mode confinement. To isolate the effect of SOL flow, two identical plasmas are estabished with the same external $\mathrm{D}_{2}$ fueling rate, the only difference being the location of the $\mathrm{D}_{2}$ fueling. In the reference case, $\mathrm{D}_{2}$ fueling is injected in the divertor region, thereby imposing little SOL flow above the $\mathrm{X}$-point. This case is then compared to a case in which $\mathrm{D}_{2}$ fueling (at the same rate) is applied at plasma midplane, thereby inducing a SOL flow throughout the entire upper SOL (i.e., above the X-point), which increases strongly near the divertor target due to the large level of deuterium recycling in this region. Care is taken to insure that the $\mathrm{D}_{2}$ input and exhaust rates are well matched in all cases. For the comparison discharges, an effort was made to insure that the core (e.g., electron density and temperature, $Z_{\text {eff }}$ ), and edge (e.g., neutral pressure in the divertor, ELM frequency, and $\mathrm{D}_{\alpha}$ emission) parameters are approximately the same, thereby reducing uncertainties about the effect of these parameters on the obtained enrichment values. Machine parameters for these plasmas were plasma current $\mathrm{I}_{\mathrm{p}}=1.3 \mathrm{MA}$, toroidal field $\mathrm{B}_{\mathrm{T}}$ $=1.9 \mathrm{~T}$ with the $\nabla \mathrm{B}$ drift toward the divertor target, $q_{95}=4.1$, elongation $\mathrm{K}=1.8$, and $6.5 \mathrm{MW}$ of neutral beam heating. Typical plasma parameters were: line-averaged density $=6.5 \times 10^{19} \mathrm{~m}^{-3}$;

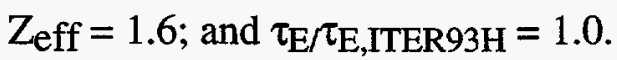

Direct measurements of the core impurity content by charge-exchange recombination (CER) spectroscopy [13] and exhaust gas impurity content via a modified Penning gauge [14] allow direct inference of the the exhaust enrichment $\left(\eta_{\text {exh }} \equiv f_{\text {exh }} / f_{\text {core }}\right)$ and compression. $\left(C_{e x h} \equiv n_{Z}^{e x h} / n_{Z}^{\text {core }}\right)$. Here, $\left(f_{\text {core }} \equiv n_{Z}^{\text {core }} / n_{e}^{\text {core }}\right), f_{\text {exh }} \equiv p_{Z}^{\text {exh }} / 2 p_{D 2}^{\text {exh }}, n_{Z}^{\text {core }}$ and $n_{e}^{\text {core }}$ are the impurity and electron densities in the core plasma (measured at $\rho=0.7$ ), $p_{Z}$ and $p_{D 2}$ are the impurity and deuterium partial pressures in the exhaust gas, and $n_{Z}^{e x h}$ is the impurity density in the exhaust gas computed assuming room temperature conditions. The effect of SOL flow is seen by comparing Case A with Case $\mathrm{B}\left(1.0 \times 10^{22} \mathrm{D} / \mathrm{s}\right)$ as well as Case C with Case $\mathrm{D}\left(5.6 \times 10^{21}\right.$ $\left.\mathrm{D}^{\circ} / \mathrm{s}\right)$. The observed exhaust enrichment $\eta_{\text {exh }}$ is observed to be consistently higher in the top fueling case, indicating a beneficial effect of SOL flow on divertor retention of impurities. The results in Table I also suggest that enrichment is sensitive to the choice of impurity. For example, in the $1.0 \times 10^{22} \mathrm{D} / \mathrm{s}$ case, helium enrichment increases $\sim 20 \%$, neon enrichment increases $\sim 90 \%$, and argon enrichment increases $\sim 200 \%$ when comparing the top $\mathrm{D}_{2}$ fueling case (Case A) with 
the divertor fueling case (Case B). Similar trends in argon enrichment have been inferred from SPRED UV measurements of argon line radiation in the core and divertor plasmas [4].

The variation with divertor density, as has been observed on ASDEX-Upgrade [15] and TdeV [16], is also recovered when comparing cases with no SOL flow, namely Case B with Case D. Enrichment is observed to increase for both neon and argon as the divertor density was increased. Both the absolute enrichment values and the degree of improvement is dependent on the impurity chosen, as only a $20 \%$ increase is observed for neon while a $200 \%$ increase is observed for argon. These results are consistent with experimental data and code calculations on ASDEX-Upgrade $[17,18]$ which suggests that the ionization mean free path of the impurity plays a strong role in the divertor retention of these impurities.

Typically, confinement in ELMing $\mathrm{H}$-mode discharges suffers when strong $\mathrm{D}_{2}$ gas injection is applied without active pumping $[19,20]$. In contrast, plasma confinement in these "puff and pump" discharges is observed to be fairly insensitive to either the presence or magnitude of gas injection up to injection rates of $2.45 \times 10^{22} \mathrm{D} / \mathrm{s}$. The robustness in confinement in these cases is correlated with the fact that the electron density and temperature (and hence pressure) at the edge "pedestal" and at the separatrix are insensitive to the magnitude of the flow. The correlation between energy confinement and the edge pressure pedestal in DIII-D H-mode plasmas has been established in previous studies [21]. Conversely, the density in the SOL increases with the flow level to as high as $1.5 \times 10^{19} \mathrm{~m}^{-3}$ while the electron temperature remains approximately $10 \mathrm{eV}$, extending spatially outward as far as the Thomson scattering diagnostic can measure in DIII-D. Projected to the midplane, this corresponds to approximately $6 \mathrm{~cm}$, compared to typical SOL widths of $\sim 1 \mathrm{~cm}$ at similar conditions without gas puffing. Such a density profile provides excellent screening of impurities emanating from the vessel wall surrounding the core plasma as typical ionization mean free paths for helium, neon, and argon at $0.025 \mathrm{eV}$ are $9.5 \mathrm{~cm}, 0.8 \mathrm{~cm}$, and $0.2 \mathrm{~cm}$, respectively. It should be pointed out that these features are not unique to this technique, as similar confinement properties and SOL density profiles are found in partially detached divertor (PDD) conditions in DIII-D. This technique also has the beneficial effect of reducing the ELM amplitude (in terms of $D_{\alpha}$ recycling) by approximately a factor of two relative to those found in standard ELMing $\mathrm{H}$-mode conditions. This reduction is accompanied by a proportional increase in ELM frequency such that the time-integrated energy carried out by the ELMs is approximately the same, but the instantaneous perturbation on the edge and divertor plasma induced by each ELM is much smaller.

Recent experiments have also been carried out using the "puff and pump" technique with recently installed hardware in the upper divertor of DIII-D. Because of diagnostic limitations, direct measurements of impurity enrichment in the upper pumping plenum were not available for 
these experiments. However, estimates of the impurity enrichment can be made by inferring the impurity partial pressure in the upper plenum from particle balance considerations (i.e., assuming that the input rate is equal to the exhaust rate). In this case, the impurity partial pressure is given by $p_{Z}=\Phi_{z} / Q_{z}$ where $\Phi_{z}$ is the impurity gas injection rate, and $Q_{z}$ is the pumping speed for the impurity. $\Phi_{z}$ and $Q_{z}$ are known from off-line calibrations. Using this method, similar trends in impurity enrichment are found as were observed with the lower divertor (i.e., enrichment increasing with SOL flow with the effect being largest for argon). Argon enrichment in the best case is $\sim 20$ with the characteristic time scale for removing argon as low as $2 \tau_{\mathrm{E}}$. For comparison, the best argon removal rate obtained with the lower divertor was approximately $4 \tau_{\mathrm{E}}$. This data suggests that divertor geometry does have an effect on impurity enrichment with the more closed, baffled geometry of the upper divertor in DIII-D being more favorable than the open geometry of the lower divertor. 

-

10

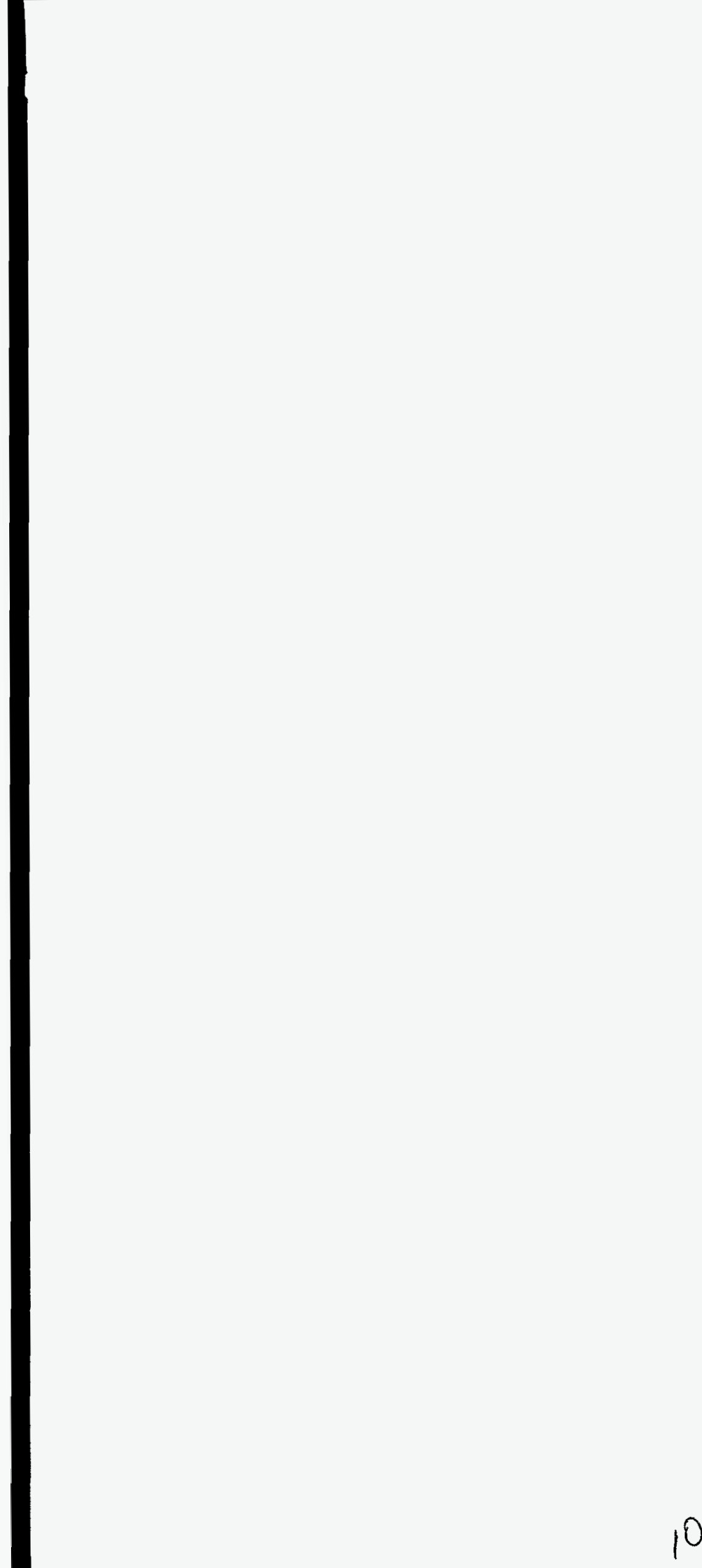




\section{PRODUCING RADIATIVE PLASMAS USING THIS METHOD}

The successful application of this technique to produce radiative divertor conditions is very sensitive to the choice of impurities. In DIII-D, one must always consider the effect of line radiation from carbon when attempting to produce any radiative condition. Generated from erosion of the graphite tiles protecting the DIII-D vacuum vessel, carbon is the primary impurity in all DIII-D plasmas and generally accounts for more than one-half of the radiation in unseeded discharges [22]. Argon has been chosen as the seeded impurity for this study as its radiation properties are the most suitable of the noble gases for the DIII-D edge and divertor. This choice is based upon the fact that the radiation cooling rates for argon are similar to those for carbon in the electron temperature range encountered in the DIII-D edge and divertor, assuming either coronal or non-coronal equilibrium. For the same impact on core fuel dilution $\left(\sim \mathrm{Zf}_{\mathrm{Z}}\right)$, the similarity in the cooling rates implies that argon enrichment must exceed carbon enrichment by a factor of 3 to obtain argon divertor radiation levels that are comparable with the intrinsic carbon radiation. The results of Table 1, assuming carbon to have an enrichment value bounded by the observed helium and neon enrichments, suggests that this should be possible. However, success is predicated upon using the "puff and pump" technique to obtain high argon enrichment values and that the obtained enrichment is not overly sensitive to the degree of radiation present.

Using this technique, a radiative plasma has been produced that has many of the aspects required by the radiative "solution" embodied in the ITER design criteria (see Table 2). The temporal evolution of various waveforms of a representative discharge is shown in Fig. 1. This particular discharge was carried out in a lower-single null diverted discharge with $R_{0}=1.68 \mathrm{~m}$, a $=0.60 \mathrm{~m}, \mathrm{I}_{\mathrm{p}}=1.3 \mathrm{MA}, \mathrm{B}_{\mathrm{T}}=1.9 \mathrm{~T}$ with the $\nabla \mathrm{B}$ drift toward the divertor target, $q 95=4.1$, and $\mathrm{K}=$ 1.8. By necessity, these discharges have long $(\sim 3.5 \mathrm{~s})$, steady-state phases. Neutral beam injection (NBI) begins shortly after the plasma current has reached flat-top [Fig. 1(a)]. A SOL flow is then induced by increasing $\mathrm{D}_{2}$ gas injection to the desired level at $1.5 \mathrm{~s}$ and then maintaining a constant fueling rate until the end of the discharge at $5.0 \mathrm{~s}$, while simultaneously exhausting gas at the same rate [Fig. 1(b)]. Argon fueling begins at $2.0 \mathrm{~s}$ and is maintained constant until $4.0 \mathrm{~s}$ [Fig. 1(c)]. In this particular discharge, the $\mathrm{D}_{2}$ gas is introduced at the rate of $2.45 \times 10^{22} \mathrm{D}^{\circ} / \mathrm{s}$ near the stagnation point at the top of the machine. Argon is injected directly into the divertor plasma at the rate of $1.26 \times 10^{21} \mathrm{Ar} / \mathrm{s}$. The neutral beam input power in this case is $11.9 \mathrm{MW}$.

Before argon injection and within approximately $500 \mathrm{~ms}$ after the end of argon injection, the total radiated power, determined by tomographic reconstruction of signals from two 24-channel bolometers, represents approximately $50 \%(\sim 6.0 \mathrm{MW})$ of the total input power $\left(\mathrm{P}_{\mathrm{NBI}}+\mathrm{P}_{\mathrm{OH}} \approx\right.$ 
Table 1

Measured enrichment $\left(\eta_{\text {exh }}\right)$ and compression $\left(C_{e x h}\right)$ for various flow levels and impurities

\begin{tabular}{|l|l|l|l|l|l|l|l|l|}
\hline & \multicolumn{2}{|c|}{ Case A } & \multicolumn{2}{c|}{ Case B } & \multicolumn{2}{c|}{ Case C } & \multicolumn{2}{c|}{ Case D } \\
\hline Fueling Location & \multicolumn{2}{|c|}{ Top } & \multicolumn{2}{c|}{ Divertor } & \multicolumn{2}{c|}{ Top } & \multicolumn{2}{c|}{ Divertor } \\
\hline Fueling Rate( $\left(\mathrm{D}^{\circ} / \mathrm{s}\right)$ & $1.05 \times 10^{22}$ & \multicolumn{1}{|c|}{$1.05 \times 10^{22}$} & $5.6 \times 10^{21}$ & \multicolumn{2}{|c|}{$5.6 \times 10^{21}$} \\
\hline & $\eta_{\text {exh }}$ & $C_{\text {exh }}$ & $\eta_{\text {exh }}$ & $C_{\text {exh }}$ & $\eta_{\text {exh }}$ & $C_{\text {exh }}$ & $\eta_{\text {exh }}$ & $C_{\text {exh }}$ \\
\hline Helium & 1.1 & 6.1 & 0.9 & 4.3 & $\mathrm{n} / \mathrm{a}$ & $\mathrm{n} / \mathrm{a}$ & $\mathrm{n} / \mathrm{a}$ & $\mathrm{n} / \mathrm{a}$ \\
\hline Neon & 2.3 & 14.2 & 1.2 & 7.8 & 1.6 & 6.2 & 1.0 & 4.6 \\
\hline Argon & 17.0 & 85.0 & 6.0 & 28.5 & 3.7 & 11.4 & 2.1 & 6.2 \\
\hline
\end{tabular}

Table 2

Comparison of the relevant ITER design criteria with those obtained using the "puff and pump" technique with argon on DIII-D

\begin{tabular}{|l|l|l|}
\hline & ITER & DIII-D \\
\hline$P_{\text {rad }}^{\text {tot }} / P_{\text {input }}$ & 0.83 & 0.72 \\
$\left(P_{\text {rad }}^{\text {div }}+P_{\text {rad }}^{S O L}\right) / P_{\text {input }}$ & 0.33 & 0.55 \\
$P_{\text {rad }}^{\text {core }} / P_{\text {input }}$ & 0.16 & 0.17 \\
$Z_{\text {eff }}$ & $<1.8$ & 1.85 \\
$\tau_{E} / \tau_{E, I T E R 93 H}$ & 0.85 & 1.1 \\
$\tau_{E} / \tau_{E, I T E R 89 P}$ & 1.8 & 1.7 \\
$\tau_{E} / \tau_{E, I T E R 97 E P S}$ & 0.85 & 0.98 \\
\hline ELMs & Type I & Type I \\
\hline
\end{tabular}

*Achieved simultaneously and in quasi-steady-state. 

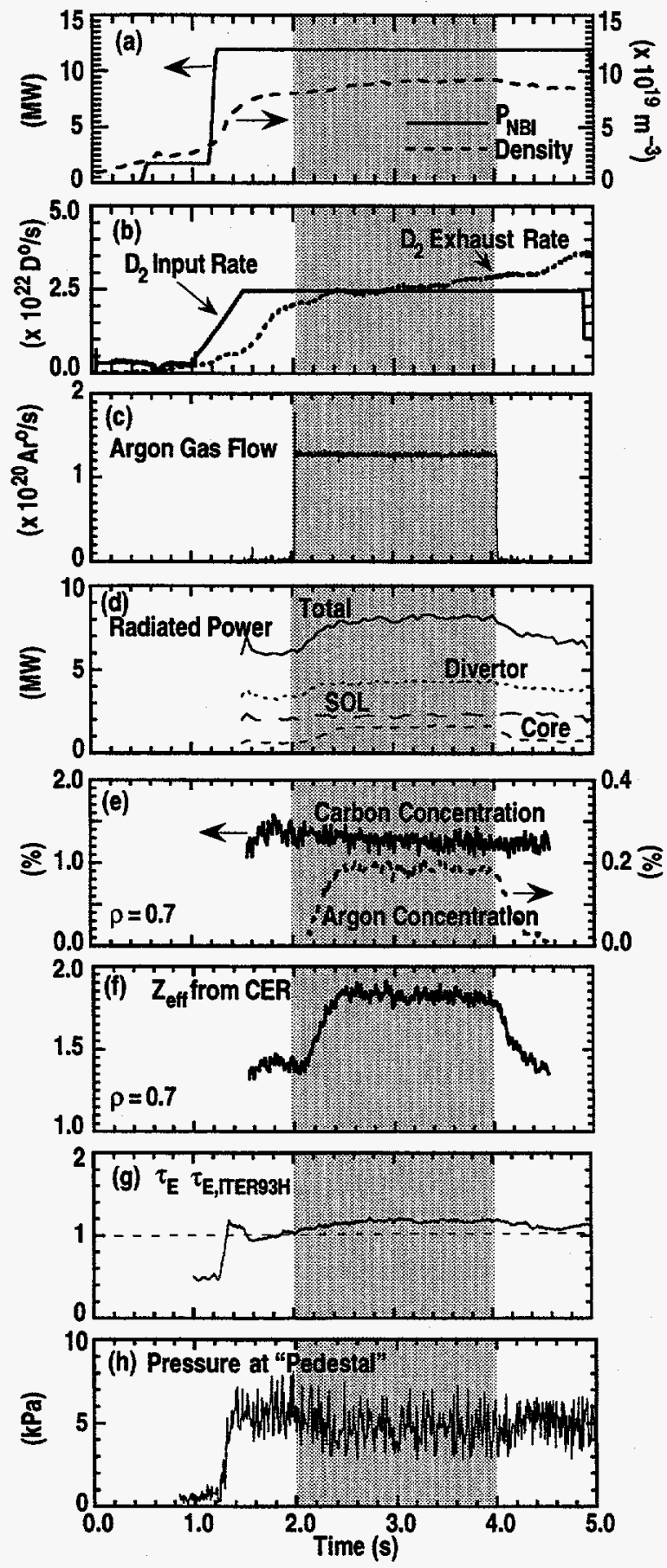

Fig. 1. Temporal evolution of the (a) input power and line-averaged electron density; (b) deuterium input and exhaust rate, $(c)$ argon input rate, $(d)$ radiation power balance; $(e)$ carbon and argon concentration at $\rho=0.7$; (f) $Z_{\text {eff }}(g) \tau_{E} / \tau_{E, T E R 93 H}$; and (h) the "pedestal" electron pressure in a radiative discharge produced via argon injection simultaneous with strong $D_{2}$ injection and divertor exhaust. The pedestal pressure is obtained from a hyperbolic tangent fit to the Thomson Scattering profile [26]. 
11.9 MW), with $\mathrm{P}_{\text {rad,div }}: \mathrm{P}_{\mathrm{rad}, \mathrm{SOL}}: \mathrm{P}_{\mathrm{rad}, \text { core }}(\mathrm{MW})=3.5: 2.0: 0.5$ [Fig. 1(d)]. The peak heat flux incident on the outer divertor target, inferred from IRTV measurements, is $\sim 2.0 \mathrm{MW} / \mathrm{m}^{2}$ during the initial phase. Note that because there is substantial radiation prior to argon injection, this peak heat flux is a factor of two lower than the value normally obtained at these power levels with no external gas injection [23]. During this phase, carbon is the dominant impurity in the core plasma with $Z_{\text {eff }} \approx 1.4$ [Fig. 1(e) and Fig. 1(f)], and carbon and deuterium are the main radiating constituents as determined by divertor SPRED measurements (Fig. 2). The primary radiating lines are $\mathrm{CVI}$ at $1550 \mathrm{~A}$ and $\mathrm{L}_{\alpha}$ at $1216 \mathrm{~A}$.

After argon injection begins at $2.0 \mathrm{~s}$, the total radiated power fraction increases to $\sim 70 \%$ (8.5 MW) on an argon equilibration time scale $\left(-250 \mathrm{~ms}\right.$ in this case) with $\mathrm{P}_{\text {rad,div: }} \mathrm{P}_{\mathrm{rad}, \mathrm{SOL}}$ : $\mathrm{P}_{\text {rad,core }}(\mathrm{MW})=4.3: 2.4: 1.8$. Steady-state conditions are then maintained for the remainder of the argon injection phase. Argon radiation is observed to increase in both the core and divertor plasmas during this phase. The increase in $\mathrm{P}_{\text {rad,core }}$ is consistent with calculations of the expected argon radiation in the core plasma using the measured values of electron density, electron temperature, and argon fraction, and assuming coronal equilibrium (Fig. 3). In the divertor plasma, argon line radiation is also observed to increase with the primary line being the Na-like $\mathrm{Ar}$ VIII line at $700 \mathrm{~A}$ and the Mg-like Ar VII line at $585 \mathrm{~A}$. However, carbon radiation increases also, and it remains the dominant radiator throughout the argon injection phase (Fig. 2). The core carbon fraction does not change during this phase while the argon fraction increases to $\sim 0.20 \%$, resulting in $Z_{\text {eff }} \approx 1.85$. The incremental $Z_{\text {eff }}$ (i.e., $Z_{\text {eff }}-1=0.85$ ) in this case is a factor of 2 smaller than that predicted by the scaling of Matthews et al. [Matthews, 1997 \#62], consistent with the fact that the radiation is predominantly from the divertor region. The argon fraction in the exhaust gas is $0.60 \%$, resulting in an argon enrichment of 3.0.

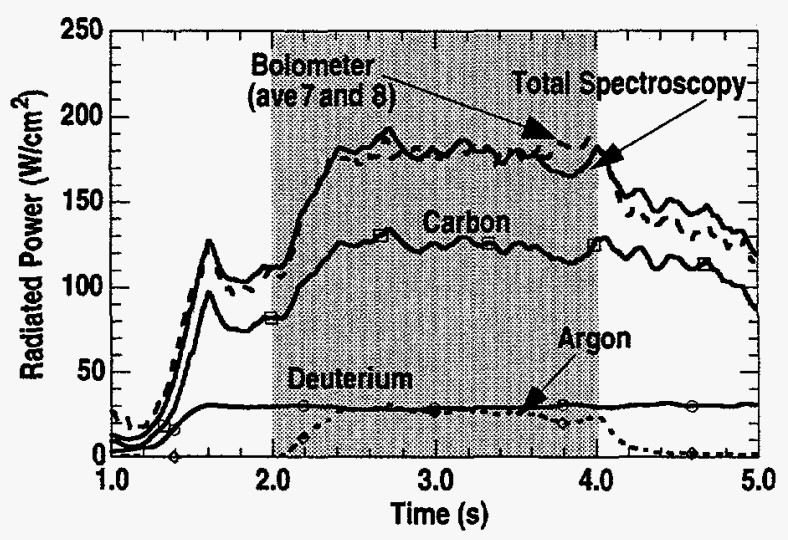

Fig. 2. Comparison of the radiated power measured by a SPRED UV instrument (viewing the lower divertor X-point with a $5 \mathrm{~cm}$ radial extent) with that measured by two bolometer channels with similar lines of sight for the discharge shown in Fig. 2. Also shown is the amount of radiation from the primary radiating constituents in the divertor: carbon, argon, and deuterium. 


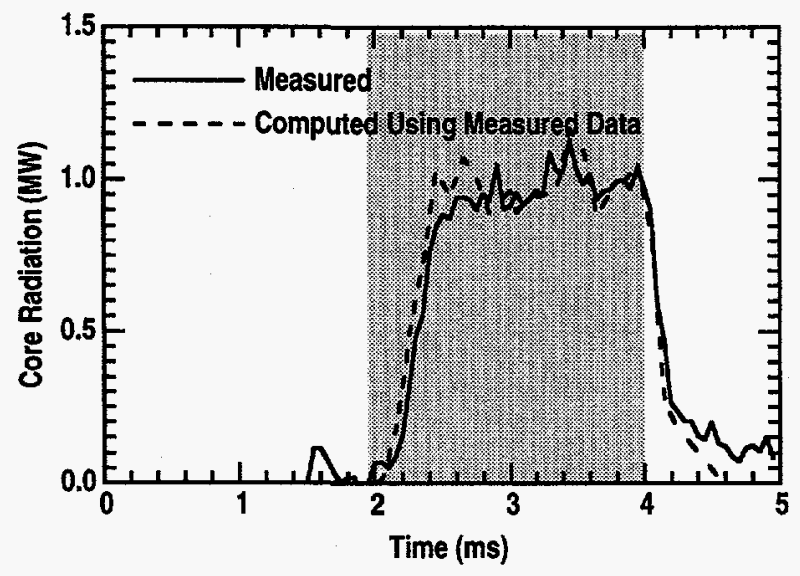

Fig. 3. Comparison of the measured increase in the core radiated power subsequent to argon injection in the discharge shown in Fig. 2 (solid line) with that computed using the formula $\ln _{\text {vol }}^{2} f_{A r} L_{A r}\left(T_{e}\right) d V$ with experimentally measured $n_{e}, f_{A r}$, and $T_{e}$,

The increase in total radiated power is accompanied by a factor of 2 decrease in the total and peak power flux incident on the outer divertor target plates. The peak particle flux, measured by a Langmuir probe array, is reduced from $70 \mathrm{~A} / \mathrm{cm}^{2}$ to $25 \mathrm{~A} / \mathrm{cm}^{2}$ during the argon injection phase. However, the outer divertor leg remains attached as the particle flux profile remains peaked at the separatrix location even though the radiative power level reaches $70 \%$. Furthermore, the measured $D_{\alpha} / D_{\beta}>20$ throughout the divertor region, indicating that significant recombination is not occuring [24]. Global energy confinement is not affected by the introduction of argon with $\tau_{\mathrm{E}}$ $=1.7 \tau_{\text {E,ITER89P }}=1.1 \tau_{\text {E,ITER93H }}=0.95 \tau_{\text {E,JET-D3D }}[$ Fig. $1(\mathrm{~g})]$. Furthermore, there is little deterioration in the edge plasma during the argon injection phase as the pedestal pressure is approximately the same as in the pre-argon phase [Fig. 1(h)]. ELMs remain type I in character with the ELM frequency increasing to $200 \mathrm{~Hz}$ during the argon injection phase. Note that there appears to be a slight increase in core energy confinement at the onset of argon injection [Fig. 1(g)]. Since there are no signs of improved core confinement (e.g., density peaking, increased rotational shear), it is surmised that this increase is due to a reduction in the power flow through the edge region as a result of an increase in core radiation.

As expected, the radiation power balance was found to be dependent on the argon injection rate. Figure 4(a) shows the fraction of radiation from the various reservoirs during an argon injection rate scan. The radiated power in the core, SOL, and divertor increases with argon injection rate with the majority of the increase in radiated power being core radiation. This increase in core radiation is accompanied by a decrease in H-mode confinement [Fig. 4(b)]. However, the radiative efficiency of the divertor plasma (defined here as $\mathrm{P}_{\mathrm{rad}, \mathrm{div}} /\left(\mathrm{P}_{\mathrm{input}}\right.$ - 


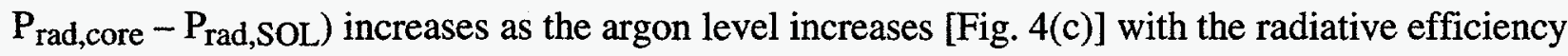
approaching $60 \%$ in the best case. This observation suggests that the ability of the divertor to radiate energy has been increased by the introduction of argon while still maintaining viable $\mathrm{H}$-mode properties at the plasma edge. The data in Fig. 4 suggest that we have not reached the point at which the response of core radiation and plasma confinement becomes non-linear with the argon level as has been seen in previous neon expeirments on DIII-D [22]. Furthermore, the linear dependence of all these parameters on argon injection rate over the wide range in radiating power suggests that feedback control of the radiated power should be possible.
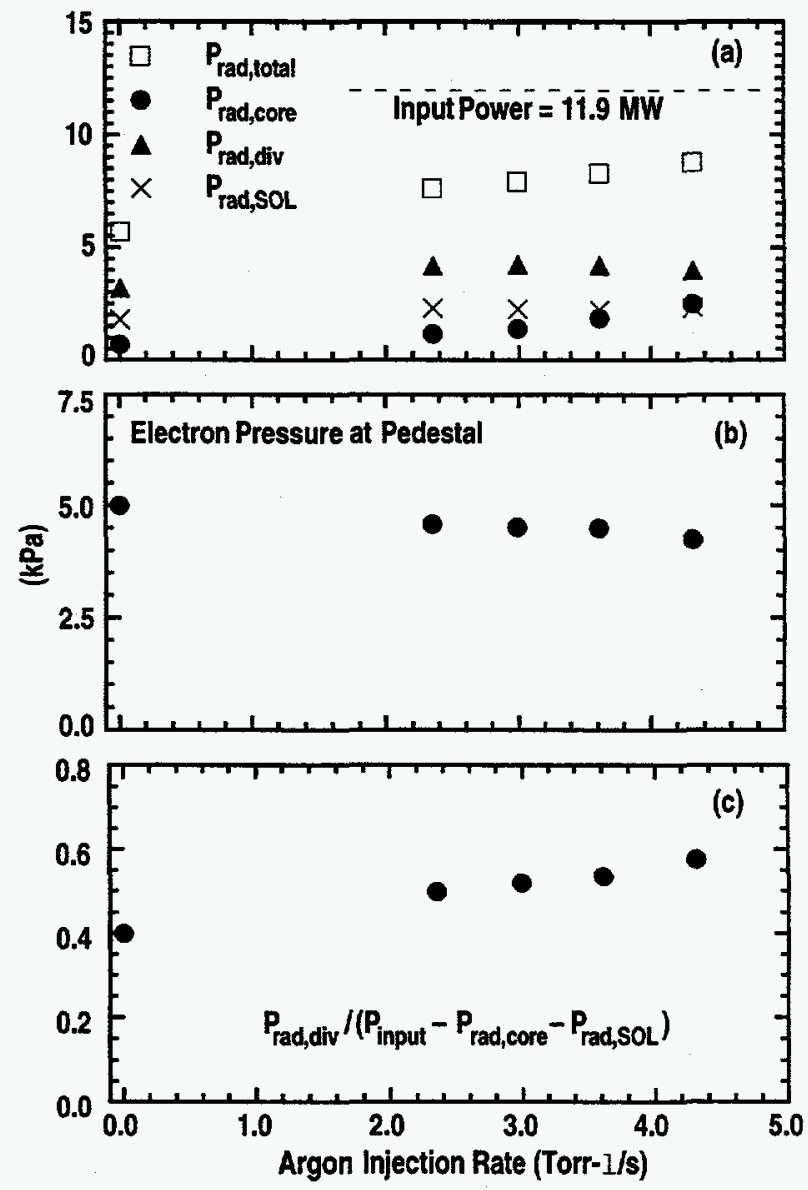

Fig. 4. Variation of (a) radiative power balance; (b) core confinement and (c) "radiative" efficiency of the the divertor plasma during an argon injection rate scan with $P_{i n j}=12 \mathrm{MW}$ and $\Phi_{D 2}=2.45 \times 10^{22} \mathrm{D} \%$. 


\section{DISCUSSION}

The results described in Section 3 indicate that using the "puff and pump" technique with argon can be an effective means of producing radiative plasmas in DIN-D that meet many of the ITER requirements simultaneously. However, because carbon is still the primary radiator in the divertor plasma of these discharges, the extrapolability of such a technique is an outstanding issue. To produce similar divertor radiation levels without any carbon present, argon divertor radiation must be increased by a factor of 5 from the present level (Fig. 3). Without fundamental changes in other parameters, increasing the argon radiation by simply adding more argon is not possible in this case as argon radiation in the core plasma will increase proportionately, thereby reducing the amount of power available for radiation in the divertor. Although there are similarities between these discharges and completely detached H-mode (CDH-mode) plasmas produced on ASDEX-Upgrade [Neuhauser, 1995 \#67], the plasmas described here have fundamental advantages over $\mathrm{CDH}$-mode with lower $\mathrm{Z}_{\mathrm{eff}}$ (1.9 versus 3.0) and higher $\tau_{\mathrm{E}} / \tau_{\mathrm{E}, \text { ITER89P }}$ (1.7 versus 1.5 ). Furthermore, whereas the divertor plasma is completely detached in the CDH-mode regime with minimal power flow through the edge plasma and Type III ELMs, the plasmas described here have substantial power flow through the plasma edge, Type I ELMS, and the outer divertor leg is still attached, albeit with substantially reduced incident particle and heat fluxes.

In terms of extrapolation, there are two options that may help to improve the situation: 1) improved argon enrichment and 2) higher reactivity core plasmas (i.e., lower $n_{\mathfrak{e}}$ and higher $T_{j}$ ). As mentioned previously, argon enrichment in the best radiative case is $\sim 3.0$, compared to $\sim 17.0$ in the best case obtained in trace-level experiments. This reduction in enrichment is believed to be due to the fact that the inner divertor leg is detached in the radiative discharge. The reduction in ionization capability of the inner divertor leg provides a path for argon neutrals to escape from the divertor plasma and not be subject to the applied $\mathrm{D}_{2}$ flow. Spectroscopic measurements of $\mathrm{Ar}$ recycling in the divertor region support this hypothesis, but more work is required to clarify this issue. If one could recover the argon enrichment value of $\sim 17$ of the trace-level case, then the argon injection rate could be increased by roughly a factor of 5 with the same impact on the core plasma. Careful control of the onset of divertor detachment in both divertor legs is required for this approach to work, implying the need for independent pumping of both divertor legs. Installation of the full upper, RDP hardware in DIII-D should provide this flexibility in the near future. Increasing the core reactivity has several inherent benefits in terms of reducing the radiation from the core plasma for a given argon fraction. Firstly, higher plasma temperatures will 
reduce the radiative effectiveness of argon in the main plasma. Secondly, since both line radiation and bremmstrahlung scale as $\sim n_{e}^{2} f_{Z}$, any reduction in electron density provides significant additional headroom in the allowable argon fraction. However, a lower electron density implies that substantial improvements in both deuterium and impurity compression will be necessary to provide adequate radiation in the divertor region and, hence, may be impractical.

In conclusion, a radiative plasma which meets many of the relevant criteria embodied in the ITER design has been produced on DIII-D using strong, induced SOL flow and argon injection. A comparision of the relevant requirements for ITER with the results obtained in this experiment are shown in Table 2. Furthermore, the argon impurity fraction obtained here $(\sim 0.20 \%)$ is consistent with the maximum fraction allowed in ITER as estimated by computational simulations [25]. Previous analytic estimates show that the maximum heat flux reduction in ITER that could be expected given this argon fraction would be $\approx 50 \%$ [1]. However, assuming that an argon enrichment consistent with this experiment (i.e., $\eta_{\text {exh }}=3.0$ ) can be achieved on ITER, then this percentage would increase to over $67 \%$, consistent with the ITER criteria that $P_{\text {target }} / P_{\text {loss }}=33 \%$. The results described in Section 2 indicate that even higher divertor enrichment of argon $\left(\eta_{\text {exh }} \approx 20\right.$ ) can be obtained using induced SOL flow and that a more closed, baffled divertor geometry may increase the argon enrichment further. Finally, it is worth noting that the "solution" described here embodies many of the favorable aspects of a "hybrid" radiative solution in which low- $Z$ impurity radiation predominates in the divertor and radiation from a high-Z impurity embellishes this divertor radiation while providing additonal radiation in the core plasma. 


\section{REFERENCES}

[1] D.E. Post et al., Phys. Plasmas 2 (1995) 2328.

[2] M.J. Schaffer et al., Nucl. Fusion 8, (1995) 1000.

[3] M.J. Schaffer et al., J. Nucl Mater 241-243 (1997) 585.

[4] M.R. Wade et al., "Impurity Enrichment Studies with Induced Scrape-Off Layer," submitted to Nucl. Fusion (1998).

[5] K. Thomson et al., Nucl. Fusion 34 (1994) 131.

[6] G. Janeschitz et al., Proc. of the 16th IAEA Fusion Energy Conference, Montreal, Canada, 1996 (IAEA), Vol. 2, 755.

[7] T.W. Petrie et al., J. Nucl.-Mater. 196-198 (1992) 848.

[8] T.W. Petrie et al., Nucl. Fusion 37 (1997) 643.

[9] G. Matthews et al., J. Nucl. Mat. 196-198 (1997) 450.

[10] J. Neuhauser et al., J. Nucl. Mater. 121 (1984) 194.

[11] S.I. Krasheninnikov, Contrib. Plasma Phys 28 (1988) 465.

[12] D.E. Post et al., J. Nucl. Mater. 121 (1984) 171-177.

[13] P. Gohil et al., in Proceedings of the 14th Symposium on Fusion Engineering, San Diego, 1992 (IEEE, New York, 1992), vol. 2, pp. 1199.

[14] C.C. Klepper et al., Rev. Sci. Instrum. 68 (1997) 400.

[15] H.S. Bosch et al., Phys. Rev. Lett. 76 (1996) 2499-2502.

[16] R. Décoste et al., Proc. of the 16th International Conference on Fusion Energy, Montreal, Canada, 1996 (IAEA), Vol. 1, pp. 129.

[17] H.S. Bosch et al., J. Nucl. Mater 241-243 (1997) 82.

[18] D.P. Coster et al., J. Nucl. Mater. 241-243 (1997) 690.

[19] T.W. Petrie et al., Nucl. Fusion 33 (1993) 929.

[20] L.D. Horton, Plasma Phys. Cont. Fusion 38 (1996) A269.

[21] T.H. Osborne et al., Proc. of the 24th EPS Conference on Controlled Fusion and Plasma Physics, Berchtesgaden, Germany, 1997 (European Physical Society), Vol. III, 1101.

[22] R.C. Isler et al., Plasma Phys. Cont. Fusion 4 (1997) 355.

[23] C.J. Lasnier et al., this conference (1998).

[24] R.C. Isler et al., Plasma Phys. Cont. Fusion 4 (1997) 2989.

[25] J. Mandrekas et al., Nucl. Fusion 37 (1997)1015.

[26] R.J. Groebner et al., Proc. of the 16th International Conference on Fusion Energy, Montreal, Canada, 1996 (IAEA), Vol. 1, 767. 
20 


\section{ACKNOWLEDGMENT}

Work supported by U.S. Department of Energy under Contract Nos. DE-AC03-89ER51114, DE-AC05-96OR22464, W-7405-ENG-48, DE-AC02-76CH03073, and Grant No. DE-FG0395ER54294. 